\title{
Update From Sri Lankan Twin Registry: Establishment of a Population-Based Twin Register and Ongoing Project on Common Mental Disorders, Alcohol Abuse and Suicidal Ideations
}

\author{
Sisira Hemananda Siribaddana,' Waduthanthrige Danushki Siriwardane,' Suwin Nilanga Hewage,' \\ Athukoralage Don Manjula Deshapriya Athukorale,' Athula Sumathipala, ${ }^{2}$ and Matthew Hotopf ${ }^{3}$ \\ ' Sri Lanka Twin Registry, Institute of Research and Development, Battaramulla, Sri Lanka \\ ${ }^{2}$ Section of Epidemiology, Institute of Psychiatry, Kings College, University of London, London, United Kingdom \\ ${ }^{3}$ Department of Psychological Medicine, Institute of Psychiatry, Kings College, London, United Kingdom
}

\begin{abstract}
The Sri Lankan Twin Registry began as a volunteer register in 1997. Previously, we have shown doorto-door surveys as the best option to build a population-based twin register of older, adult twins. Our aim was to build a population-based twin register in the Colombo district and use it for twin studies on common mental disorders. We aimed to identify a random sample of 4000 twins ascertained through the twin census. The Colombo district is divided into 13 divisional secretariat divisions (DSDs) and each division is further divided into Grama Niladari divisions administratively. Grama niladaris (GNs) are civil servants and visit each household in order to update the electoral register. GNs were used to do a census of twins while they updated the electoral register. The correlation between population density and twin rate among DSDs was .81, and between twin rate and the percentage of returned forms (from each DSD) was .74. We received 9648 forms notifying about twins and multiples. After removing the duplicates and information about twins who live in other districts, there were 17,406 multiples remaining. After incorporating twins and multiples from various other feasibility studies we now have 19,040 multiples with 8.46 twins per 1000 people in the Colombo district.
\end{abstract}

\section{Background}

The Sri Lankan Twin Registry (SLTR) began as a volunteer register in 1997 (Sumathipala, Fernando, et al., 2000). The register quickly gained momentum and 9204 twins responded to advertisements in the media and registered. We translated and validated a zygosity determination questionnaire (Sumathipala, De Silva, et al. 2000). In the previous Twin Research special issue on twin registries we described our work regarding ethical issues, welfare and advocacy activities in the multiple birth foundation (Sumathipala et al., 2002). Since 1999 , we have carried out several feasibility studies on different methods to build-up a population-based twin register (Sumathipala et al., 2001, 2003). These studies revealed that while it was possible to trace younger twins from birth records, rapid urbanisation and internal migration meant that older twins could not be traced in sufficient numbers to make this a feasible method. We predicted a doorto-door survey would be the best way to build a population-based twin register of older, adult twins (Sumathipala et al., 2003). We report here on the successful execution of a door-to-door survey in creating a population-based twin register.

\section{Project on Common Mental Disorders}

Our strategy was to build a population-based twin registry through a specific project. In this update we describe a relatively low cost method to ascertain older twins (over 18 years) through a census conducted in the Colombo district. This project was funded by the Wellcome Trust and conducted as a collaboration between the Institute of Psychiatry (IOP), King's College, London; The World Health Organization's (WHO) Human Genetics Programme, and the SLTR. This collaboration was built on existing mental health

Received 1 August, 2006; accepted 9 September, 2006.

Address for correspondence: S. H. Siribaddana, Sri Lanka Twin Registry, 762/4b, Pannipitiya Rd, Battaramulla, 10120, Sri Lanka. E-mail:nipuna@stmail.lk 


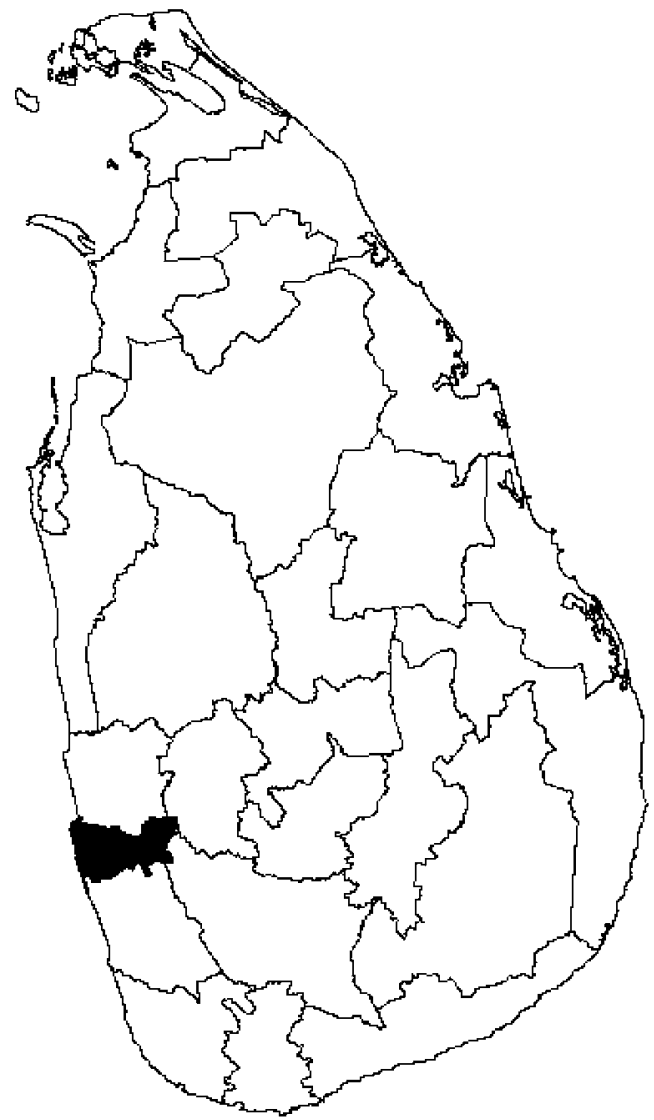

Figure 1

Colombo district in Sri Lanka.

research links between the IOP and SLTR. We also obtained clearance from ethical review committees at the IOP, WHO (Geneva) and Sri Jayewardenepura University of Sri Lanka.

Our objective was to build a population-based twin register in the district of Colombo for a twin study on common mental disorders. We aimed to identify a random sample of 4000 twins (2000 twin pairs), ascertained by the twin census. We also aimed to identify a parallel sample of 1000 nontwins ascertained using the same sampling procedure. Several features made this study unusual: First, it was based on a true population sample. Second, it took place in a developing country, with a population experiencing wide disparities of environmental risk factors. Third, we sought to measure the environmental risk factors directly, instead of only relying on the equal environments assumption. Finally, we aimed to identify a nontwin sample ascertained in the same way, in order to determine the degree to which twins were representative of the wider population.

We translated and adapted several questionnaires including the Composite International Diagnostic Interview (CIDI; WHO, 1997) using current and lifetime psychiatric diagnoses, the Bradford Somatic Inventory (Mumford et al., 1991), the Chalder Fatigue Scale (Chalder et al., 1993), the Childhood Experience of Care and Abuse Questionnaire (Smith et al., 2002), SF-36 Health Status Survey Questionnaire (Ware \& Sherbourne, 1992), and the Life Events Questionnaire (Bhugra \& Cragg, 1990). We developed questionnaires on suicidal ideations, exposure to war and tsunami, and socioeconomic deprivation. We trained 25 research assistants (RA), with the goal of interviewing 5000 participants. The minimum interview duration was 120 minutes. Funding was provided for buccal smear testing of same gender twins in order to determine zygosity.

\section{Colombo District Population-Based Twin Register}

For administrative purposes, Sri Lanka is divided into nine provinces and 25 districts. The district of Colombo is the most populous district (population 2,251,274), with $12 \%$ of the total population (Department of Census and Statistics, 2005; Figure 1). It is divided into 13 divisional secretariat divisions (DSDs) and each DSD is further divided into several grama niladhari divisions (GNDs). The GND is the smallest administrative unit, and is headed by a grama niladhari (GN). Colombo district has 557 GNDs. The GN is a civil servant, and visits each home in their administrative division once a year to update the electoral register. 
Table 1

Divisional Secretariat Divisions, Population, Housing Units and Level of Poverty

\begin{tabular}{|c|c|c|c|c|c|}
\hline DSD in Colombo district & Population & Density* & Housing units & $\mathrm{HI}(\%)$ & HPBPL \\
\hline Colombo & 380,946 & 21,337 & 69,800 & 12.1 & 39,819 \\
\hline Thimbirigasyaya & 266,154 & 11,895 & 54,460 & 4.4 & 9672 \\
\hline Rathmalana & 108,716 & 8269 & 25,677 & 4.2 & 4058 \\
\hline Dehiwala & 101,830 & 12,124 & 23,810 & 2.1 & 1896 \\
\hline Moratuwa & 177,563 & 9246 & 39,925 & 10.3 & 16,908 \\
\hline Hanwella & 94,001 & 644 & 24,700 & 14.2 & 12,562 \\
\hline Maharagama & 185,193 & 4958 & 42,807 & 3.5 & 5973 \\
\hline Kaduwela & 209,251 & 2385 & 52,910 & 6.0 & 11,614 \\
\hline Kolonnawa & 161,247 & 6193 & 36,133 & 8.2 & 12,292 \\
\hline Homagama & 186,050 & 1563 & 47,338 & 6.4 & 10,797 \\
\hline Kesbewa & 209,619 & 3411 & 51,234 & 5.2 & 10,326 \\
\hline Padukka & 54,338 & 518 & 15,010 & 10.7 & 5439 \\
\hline Kotte & 116,366 & 7046 & 27,031 & 2.7 & 2750 \\
\hline Total & $2,251,274$ & 3310.84 & 510,835 & 6.0 & 144,106 \\
\hline
\end{tabular}

Note: ${ }^{*}=$ population/square $\mathrm{km}$.

$\mathrm{HI}=$ Head count index = percentage of the population below the poverty line (Rs 1432).

$\mathrm{HPBPL}=$ number of household population below poverty line.

They distribute, and subsequently collect, a form to each house, in order to collect data about each occupant over 18 years. Sri Lanka has a vibrant and participatory democracy, with over $80 \%$ of the population participating in recent general and presidential elections. As failure to register on the electoral roll results in a loss of the right to vote as well as exclusion from other administrative and welfare activities carried out by the state, distribution and completion of registration forms is performed with diligence by both the administration and the electorate.

A national population census was most recently conducted in 2001. During this census all streets and byroads were marked, and housing as well as nonhousing units were identified and counted. Four of the most densely populated DSDs are situated in Colombo

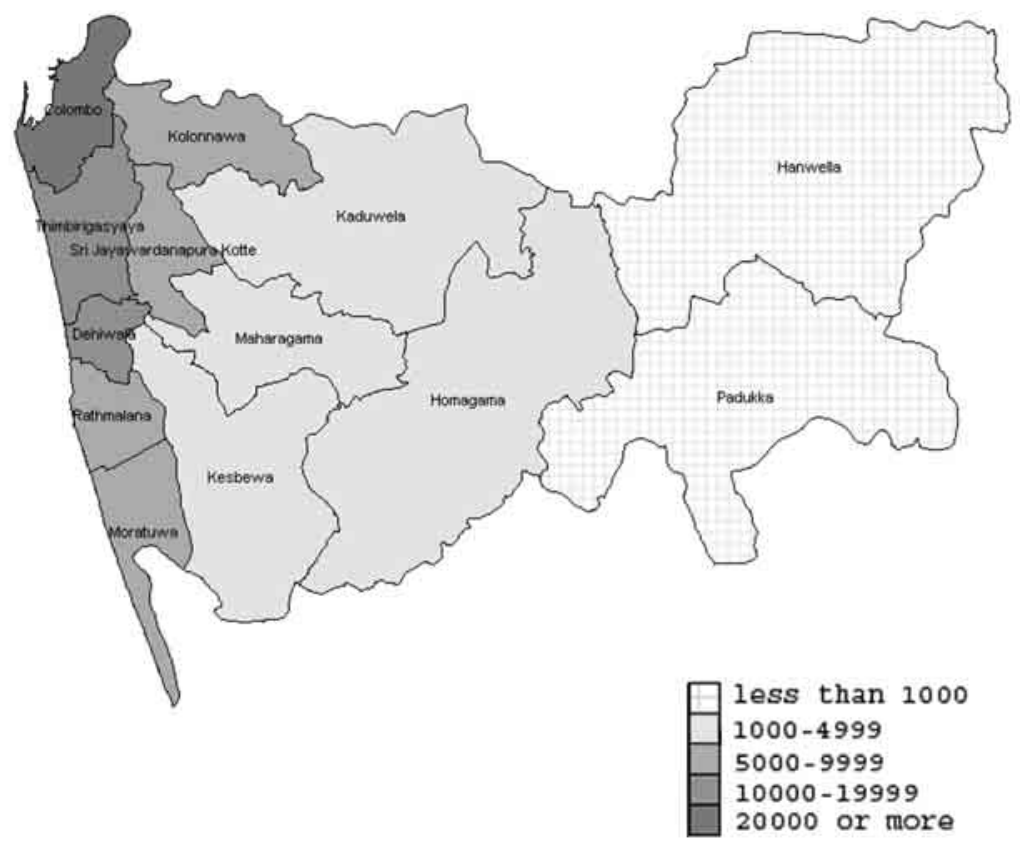

Figure 2

Population density in Colombo district. 


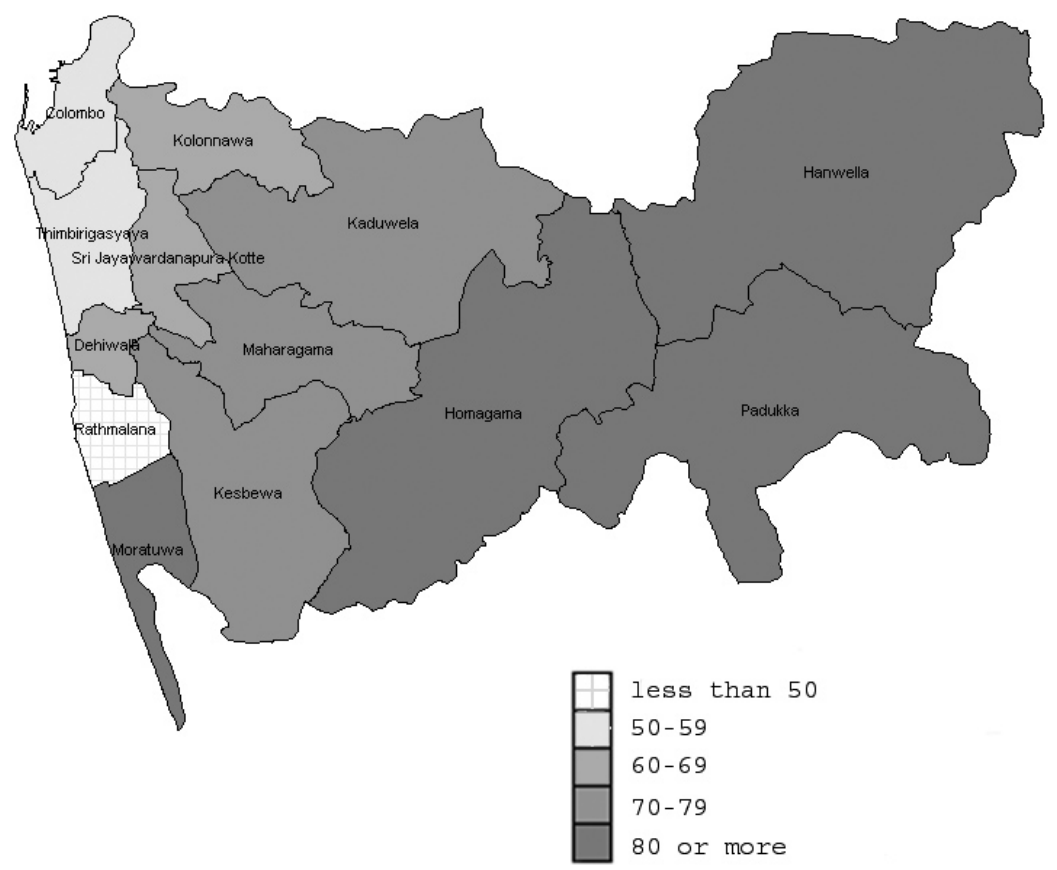

Figure 3

Percentage of forms received.

city itself (Colombo, Thimibirigasyaye) and adjacent suburbs in the south along the coast (Rathmalana, Dehiwala; Table 1 shaded rows and Figure 2).

The GNDs in these four DSD areas are therefore also heavily populated (average population per GND is 12,826 ) so GNs are assisted by electoral department officers (EDOs) to update the electoral register. The other nine DSD are semiurban and rural areas, and individual GNs conduct the electoral register update unassisted (average population per GND is 2820).
The cooperation of necessary public officials was obtained to collect data about twins during the annual update of electoral register in 2003. A separate form was devised in the three main languages of Sinhalese, Tamil and English, which inquired about the informant's name, telephone, address and details about twins known to the informant. This was distributed and collected by GNs along with the electoral register update form. GNs and EDOs were given a financial incentive for conducting the survey. In one of the four

\section{Table 2}

Percentage of Census Forms Received, Twin Pairs Reported and Twin Rate per Thousand Population

\begin{tabular}{|c|c|c|c|c|c|}
\hline DSD & Forms Distributed & Forms received & $\%$ Received & Twin pairs reported & Twin rate \\
\hline Colombo & 69,800 & 34,588 & 49.55 & 1097 & 2.88 \\
\hline Thimbirigasyaye & 54,460 & 17,737 & 32.57 & 653 & 2.45 \\
\hline Rathmalana & 25,677 & 14,353 & 55.90 & 249 & 2.29 \\
\hline Dehiwala & 23,810 & 16,156 & 67.85 & 303 & 2.98 \\
\hline Moratuwa & 39,925 & 32,494 & 81.39 & 609 & 3.43 \\
\hline Hanwella & 24,700 & 21,724 & 87.95 & 596 & 6.34 \\
\hline Maharagama & 42,807 & 30,192 & 70.53 & 1007 & 5.44 \\
\hline Kaduwela & 52,910 & 41,528 & 78.49 & 1078 & 5.15 \\
\hline Kolonnawa & 36,133 & 24,091 & 66.67 & 947 & 5.87 \\
\hline Homagama & 47,338 & 38,014 & 80.30 & 1075 & 5.78 \\
\hline Kesbewa & 51,234 & 38,458 & 75.06 & 1183 & 5.64 \\
\hline Padukka & 15,010 & 12,431 & 82.82 & 342 & 6.29 \\
\hline Kotte & 27,031 & 16,799 & 62.15 & 509 & 4.37 \\
\hline Total & 510,835 & 338,565 & 66.28 & 9,648 & 4.29 \\
\hline
\end{tabular}

Note: ${ }^{*}=$ (twin pairs/population) $\times 1000$. 


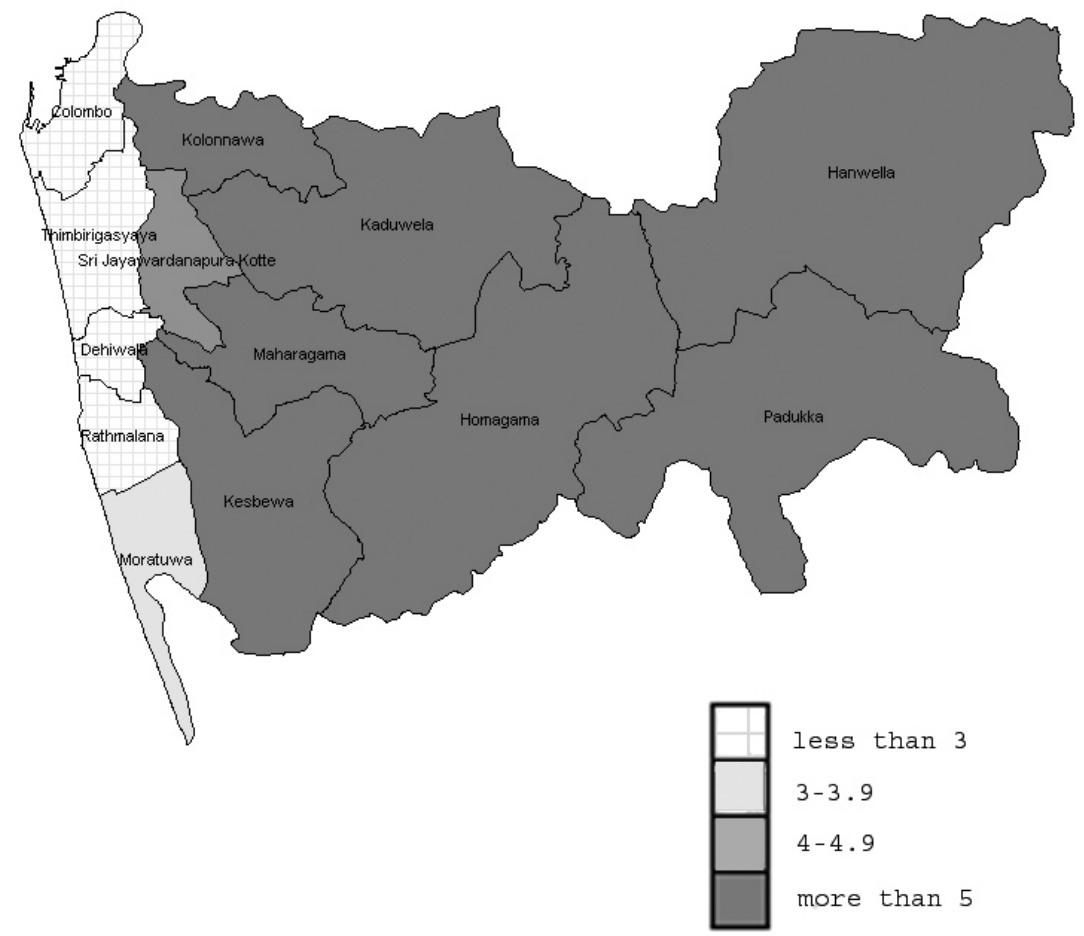

\section{Figure 4}

Number of twins per 1000 people in Colombo district.

DSD divisions (Dehiwala), GNs took a collective decision to distribute twin census forms themselves, instead of giving them to EDOs, resulting in only three DSDs where EDOs collected twin census forms.

We distributed 510,835 forms (one to every housing unit of the district), and received back $66 \%$ completed (range of 13 SDSs $33 \%-83 \%$ ). To be considered as a housing unit, three conditions needed to be met: the unit should be a place of dwelling of human beings, it should be separated from other places of dwelling, and it should have a separate entrance. This was a two-visit survey by the GN: forms were distributed and collected 6 to 8 weeks later; no penalty or coercion was exerted to ensure filled twin census forms were returned. Some occupants posted the completed forms directly to the register.

In the 489 GNDs where GNs collected the twin census forms, completion was $75.3 \%$. This compares to $49.3 \%$ completion in the 68 GNDs where EDOs and GNs collected the forms (Table 2 and Figure 2). Twin pairs were identified in $2.1 \%$ of households when GNs collected census forms and $1.3 \%$ of households when EDOs and GNs collected the forms. GNs are members of the community appointed by the government and serve as the link between the government administration and the people. As each GND is responsible for issuing identity cards, birth and death registration and other administrative and welfare activities, GNs have a close rapport with the people in their GND. GNs are available to the public 3 days per week in their offices, and they are can also usually be contacted at other times at their residence. The census officers only visit once a year to update the electoral register, and probably have less rapport with the people. Due to this, the distribution and collection of twin census forms by EDOs instead of GNs may have resulted in low returns from the areas covered by EDOs. There was a negative correlation $(r=-.81)$ between population density and the number of twin pairs (per thousand people) in the DSDs and there was a positive correlation $(r=.74)$ between the number of twin pairs (per thousand) and the percentage of returned forms (from each DSD). This shows that with increasing population density the number of twin pairs ascertained by the census decreases. It also demonstrates that as population density increases, so too does the percentage of returned and filled census forms. The correlation between the percentage of people living below the poverty line in a DSD and the number of twin pairs (per thousand) in that DSD, was .15 (Department of Census and Statistics, 2005). Although it was speculated that the percentage of completed and returned census forms and subsequently the number of twins ascertained would be low from poorer areas (DSDs) of the district, the low correlation did not support this.

\section{Data handling}

The SLTR regularly publishes a newsletter to keep the twins informed about research and other welfare activities related to twins. Once all returned addresses were checked with GNs to verify the authenticity of the data, all twins with viable addresses were sent a 
Table 3

Incorporation to the Colombo District from Volunteer Database and Other Feasibility Studies

\begin{tabular}{lr}
\hline & No of twins \\
\hline Main census & 17,406 \\
100 GN study & 270 \\
Volunteer twin database & 1173 \\
Kaduwela Kolonnawa study & 127 \\
Twin postal survey & 22 \\
Maharagama DSD survey & $42^{*}$ \\
Maradana DSD survey & $*$ \\
Government and private maternity hospital survey & $*$ \\
Sri Jayewardanepura Hospital survey & 19,040 \\
\hline Total number of twins
\end{tabular}

Note: *These data are being still entered to Colombo district twin database.

special issue of the SLTR twin newsletter, explaining the project.

We received 9648 forms notifying us about twins and multiples. After excluding the duplicates and twins where both members lived in other districts, we identified 17,406 twins and multiples. We then incorporated the multiples living in the area from the island-wide volunteer database (Sumathipala, Fernando, et al., 2000) as well as multiples ascertained through several other feasibility studies (Sumathipala et al., 2001, 2003) to create a comprehensive Colombo twin database. This database is continuously updated with new data from various feasibility studies, and with new information gathered by RAs who interview twins in the field. Currently there are 19,040 multiples in the Colombo database; 8.46 twins per 1000 people in the Colombo district.

There are 1634 twins and multiples $(8.6 \%)$ identified in previous studies that were not captured by the census (see Table 3). During the incorporation of the data from these feasibility studies there were several duplicates; 2804 twins were duplicated once, 242 twice, 18 three times, 4 pairs four times and another 4 pairs five times.

\section{$\overline{\text { Recruitment }}$}

Four thousand twins randomly selected from the Colombo database were given an information leaflet hand-delivered by an RA. After explaining the project, the twins were asked to read the information leaflet carefully and to discuss with family and friends if necessary. The RAs made a second visit to the selected twins' houses to obtain informed consent - buccal smear consent was obtained separately.

Interviews with 2623 twins and 635 singletons have been completed to date -198 twins $(7.5 \%)$ refused, and 1002 twins (38.2\%) were deemed unsuitable for the study. This unsuitability was due to multiple reasons: one or both of the pair had died or gone abroad, the address was unknown, the twins were unable to speak Singhalese (the interview language), no twins were at the given address, or the mentioned pair were not twins.

\section{Options for future collaborations}

The SLTR is not confined to mental health research. We anticipate utilizing this valuable and comprehensive database for ethically sound, mutually beneficial and scientifically robust collaborative studies in the future.

\section{Acknowledgments}

We received funding from The Wellcome Trust (Grant Number 069629). We gratefully acknowledge Lakshmi Abeygonesekare for controlling the finances of the survey, Manori Wimalasekare for secretarial help, and D. J. S. Fernando, Peter McGuffin, Pak C. Sham, and David Ball for supervision and guidance. We would like to acknowledge the SLTR executive committee for all their help.

\section{References}

Brugha, T. S., \& Cragg, D. (1990). The List of Threatening Experiences: The reliability and validity of a brief life events questionnaire. Acta Psychiatrica Scandinavia, 82, 77-81.

Chalder, T., Berelowitz, G., Pawlikowska, T., Watts, L., Wessely, S., Wright, D., \& Wallace, E. P. (1993). Development of a fatigue scale. Journal of Psychosomatic Research, 37, 147-154.

Department of Census and Statistics. (2005). Statistical Abstract 2005. Retrieved July 29, 2006, from http:// www.statistics.gov.lk/abstr/tables/chp02/tab0206.pdf

Department of Census and Statistics. (2005). Headcount index and population below poverty line by DS Division-Sri Lanka. Retrieved July 29, 2006, from http://www.statistics.gov.lk/poverty/small $\% 20$ area $\% 2$ OreportNEW.pdf

Mumford, D. B., Bavington, J. T., Bhatnagar, K. S., Hussain, Y., Mirza, S., \& Narghi, M. M. (1991). The Bradford Somatic Inventory. A multi-ethnic inventory of somatic symptoms reported by anxious and depressed patients in Britain and the Indo-Pakistan subcontinent. British Journal of Psychiatry, 158, 379-386.

Smith, N., Lam., D., Bifulco, A., \& Checkley, S. (2002). Childhood experience of care and abuse questionnaire. Validation of a screening instrument for childhood adversity in clinical populations. Social Psychiatry and Psychiatric Epidemiology, 37, 572-579.

Sumathipala, A., De Silva, N., Siribaddana, S. H., Fernando, D. S. J., \& Abeysinghe, M. R. N. (2000). Cross cultural adaptation and preliminary validation of a zygosity determination questionnaire for Sri Lanka. Twin Research, 3, 205-212.

Sumathipala, A., Fernando, D. J., Siribaddana, S. H., Abeysinghe, M. R., Jayasekare, R. W., Dissanayake, V. 
H., \& De Silva, N. (2000). Establishment of a National Twin Register in Sri Lanka. Twin Research, 3, 202-204.

Sumathipala, A., Siribaddana, S. H., Abeysinghe, M. R. N., De Silva, N., Fernando, D. S. J., Dayaratne, D. A., De Silva, D., Warnasuriya, N. D., \& Hotopf, M. (2003). Challenges in recruiting older twins for the Sri Lankan Twin Registry. Twin Research, 6, 67-71.

Sumathipala, A., Siribaddana, S. H., De Silva, N., Fernando, D. S. J., Abeysinghe, M. R. N., Dayaratne, R., De Silva, D., Warnasuriya, N., \& Hotopf, M. (2002). Sri Lankan Twin Registry. Twin Research, 5, $424-426$.
Sumathipala, A., Siribaddana, S. H., De Silva, N., Abeysinghe, M. R. N., Sivayogam, S., \& Fernando, D. S. J. (2001). Feasibility of using different approaches for recruiting younger twins for Sri Lankan Twin Registry. Twin Research, 4, 459-463.

Ware, J. E, Jr. \& Sherbourne, C. D. (1992). The MOS 36 item short form health survey (SF 36) conceptual framework and item selection. Medical Care, 30, 473-483.

WHO, Division of Mental Health. (1997). CIDI-Core. Composite International Diagnostic Interview (Core Version 2.1). Geneva, Switzerland: Author. Retrieved September 28, 2006, from http://www.crufad.unsw.edu. au/cidi/cidi.htm 